\section{SAT0472 ULNAR OCCLUSION IS A MARKER OF GLOBAL VASCULAR DAMAGE IN SYSTEMIC SCLEROSIS: RESULTS FROM A MONOCENTRIC PROSPECTIVE STUDY OF 99 PATIENTS}

C.M. Yelnik ${ }^{1}$, D. Elodie ${ }^{2}$, C. Lamotte ${ }^{1}$, V. Sobanski ${ }^{1}$, S. Morell-Dubois ${ }^{1}$, H. Maillard ${ }^{1}$, M. Lambert ${ }^{1}$, P.-Y. Hatron ${ }^{1}$, D. Launay ${ }^{1}$, E. Hachulla ${ }^{1} .^{1}$ Département de Médecine Interne et d'Immunologie Clinique, Centre National de Référence Maladies Systémiques et Auto-immunes Rares, European Reference Network on Rare Connective Tissue and Musculoskeletal Diseases Network, Univ. Lille, CHU Lille; ${ }^{2}$ Univ. Lille, CHU Lille, EA 2694 - Santé publique: épidémiologie et qualité des soins, Département de Biostatistique, Lille, France

Background: Macrovascular damages of systemic sclerosis (SSc) were poorly investigated, and the link between macrovasculopathy and microvasculopathy of SSc, cardiovascular disease, and mortality remain unclear.

Objectives: To evaluate if macrovascular damage in SSc predicts the occurrence of new digital ulcers (DU), cardiovascular events and mortality, and to further assess the relationship between micro and macrovascular damages in SSc.

Methods: All consecutive SSc patients followed in our SSc National Reference Centre, who underwent an arterial doppler ultrasonography (aDUS) of the upper limbs, were included and prospectively followed up until October 2017. Inclusion criteria were: 1) adults; 2) a diagnosis of SSc according to 2013 ACR/EULAR criteria; 3) aDUS performed in our vascular exploration department.

Results: Ninety-nine SSc patients were included. Median follow-up duration was 35 (IQR, 21 to 39) months. Macrovascular damages mainly affected ulnar arteries, with ulnar artery occlusion (UAO) in $28(28.3 \%)$ patients (bilateral $60.7 \%)$. New DU occurred in $26(27.1 \%)$ patients, new cardiovascular event in $10(10.4 \%)$ patients, and 11 patients died during the study period. Interestingly, UAO was not associated with traditional cardiovascular risk factors (except dyslipidemia) nor with history of cardiovascular diseases, and was not predictive of new cardiovascular events. Conversely, UAO was associated with makers of microvascular damages, such as late nailfold capillaroscopy pattern ( $33.3 \%$ vs $6.8 \%$; OR $=6.88$, $95 \% \mathrm{Cl}=1.76$ to $26.82 ; \mathrm{p}=0.03)$ and was predictive of new ischaemic DU $(44.5 \%$ vs $24.8 \% ; \mathrm{HR}=2.23,95 \% \mathrm{Cl}=1.02$ to $4.86 ; \mathrm{p}=0.037$ ), pleading for a $\mathrm{SSc}$ specific vasculopathy.

Conclusions: Our study confirms that macrovascular damages are frequent in SSc patients and mainly affect ulnar arteries. Interestingly, UAO was associated with severe microvasculopathy, but not with markers of cardiovascular diseases.

Disclosure of Interest: None declared

DOI: 10.1136/annrheumdis-2018-eular.3141

\section{SAT0473 \\ CLINICAL AND ECHOCARDIOGRAPHIC ASSOCIATES OF ALL-CAUSE MORTALITY AND CARDIOVASCULAR OUTCOMES IN PATIENTS WITH SYSTEMIC SCLEROSIS}

S.E. van Wijngaarden ${ }^{1}$, M. Boonstra $^{2}$, B. Bloem ${ }^{1}$, D. Cassani ${ }^{3}$, F.C. Tanner ${ }^{3}$, S. Jordan ${ }^{4}$, O. Distler ${ }^{4}$, V. Delgado ${ }^{1}$, J.J. Bax ${ }^{1}$, J.K. de Vries-Bouwstra ${ }^{2}$, N. Ajmone Marsan'. ' department of Cardiology, Heart Lung Center, Leiden University Medical Center, ${ }^{2}$ department of Rheumatology, Leiden University Medical Center, Leiden, Netherlands; ${ }^{3}$ department of Cardiology, University Heart Center, University Hospital Zurich; ${ }^{4}$ department of Rheumatology, University Hospital Zurich, Zurich, Switzerland

Background: Cardiac events are an important cause of mortality in Systemic Sclerosis (SSc), but its diagnosis remains challenging. Left ventricular global longitudinal strain is a novel parameter derived from speckle tracking echocardiographic analysis which has been proposed to identify patient at higher risk of cardiac events.

Objectives: We aimed to identify clinical and echocardiographic (including GLS) parameters associated with all-cause mortality and cardiovascular events in SSc patients.

Methods: 408 SSc patients (344 females, age $54 \pm 14$ years.) were prospectively evaluated at baseline and follow-up (FU time 3.3 years. [IQR 1.8 to 5.5]). Cardiovascular events included: heart failure, cardiac infarction, coronary interventions, device implantation, arrhythmias, cerebral infarction, peripheral ischaemic vascular disease.

Results: All-cause mortality ( $n=37)$ or cardiovascular events $(n=57)$ occurred in 84 patients. At baseline, these patients were older $(59 \pm 14$ vs. $53 \pm 14$ years., $\mathrm{p}<0.001$ ), more often male ( 24 vs. $13 \%, p=0.018)$, more often had skin pigment changes ( 21 vs. $5 \%, p=0.011$ ), coronary artery disease ( 11 vs. $3 \%, p=0.001$ ), holter abnormalities ( 45 vs. $24 \%, p \leq 0.001$ ), increased ESR (24 [IQR 14 to 46 ] vs. 11 [IQR 6 to 25], p<0.001), worse NT-proBNP (151 [IQR 60 to 644] vs. 82 [IQR 51 to $145] \mathrm{ng} / \mathrm{L}, \mathrm{p}<0.001$ ), worse lung function test results (FVC $92 \pm 19$ vs. $104 \% \pm 21 \%$, $\mathrm{p}<0.001$; DLCO $55 \pm 17$ vs. $70 \% \pm 19 \%, p<0.001$ ), worse left ventricular diastolic function (E/E-prime ratio 9.9 [IQR 6.7 to 10.2] vs. 7.8 [IQR 6.4 to 9.7 ], $p<0.001$ ), higher systolic pulmonary artery pressure $(31 \pm 12 \mathrm{vs} .25 \pm 7 \mathrm{mmHg}, \mathrm{p}<0.001)$ and lower GLS ( -18.8 [IQR -20.3 to -19.5$]$ vs. -21.1 [IQR -22.1 to -20.0 ]\%, $\mathrm{p}<0.001)$. In a multivariate cox-regression analyses, age $(\mathrm{HR} 1.029,95 \% \mathrm{Cl}$ 1.006 to 1.052 ), female sex (HR $0.527,95 \% \mathrm{Cl} 0.302$ to 0.922 ), NT-proBNP (HR $1.000,95 \% \mathrm{Cl} 1.000-1.001)$, DLCO (HR 0.973, 95\% Cl 0.961-0.986) and GLS (HR 1.281, 95\% Cl 1.172-1.399) were independently associated with outcome. After dividing patients into groups according to median GLS (-20.9\%) and elevated NT-proBNP (>200 $\mathrm{ng} / \mathrm{L}$ ), survival rates were lower and cardiovascular events increased when GLS was impaired and worsened when NT-proBNP was elevated (Log-rank $p<0.001$ ).

Conclusions: In SSc patients, next to age, DLCO and NT-proBNP, GLS strongly associates with all-cause mortality and cardiovascular events, indicating that these parameters reflect relevant cardiac involvement in SSc, and as such can contribute to risk stratification and patient management.

Disclosure of Interest: None declared

DOI: 10.1136/annrheumdis-2018-eular.4662

\section{SAT0474 RACIAL DIFFERENCES IN SSC DISEASE PRESENTATION: A EUROPEAN SCLERODERMA TRIALS AND RESEARCH GROUP STUDY}

V.K. Jaeger ${ }^{1}$, E. Siegert ${ }^{2}$, E. Hachulla ${ }^{3}$, P. Airò ${ }^{4}$, G. Valentini ${ }^{5}$, M. MatucciCerinic $^{6}$, O. Distler ${ }^{7}$, F. Cozzi ${ }^{8}$, Y. Allanore ${ }^{9}$, M. Li ${ }^{10}$, M. Tikly ${ }^{11}$, U.A. Walker on behalf of EUSTAR co-authors. ' University Hospital Basel, Basel, Switzerland; ${ }^{2}$ University Hospital Charité, Berlin, Germany; ${ }^{3}$ Université de Lille, Lille, France; ${ }^{4}$ Spedali Civili, Brescia; ${ }^{5}$ University of Campania, Naples; ${ }^{6}$ University of Florence, Florence, Italy, ${ }^{7}$ University Hospital Zurich, Zurich, Switzerland; ${ }^{8}$ University of Padova, Padova, Italy; ${ }^{9}$ Cochin Hospital, Paris, France; ${ }^{10}$ Peking Union Medical College Hospital, Beijing, China; ${ }^{11}$ Chris Hani Baragwanath Hospital, Johannesburg, South Africa

Background: Genetic and environmental factors play a significant role in systemic sclerosis (SSc). African Americans are known for a higher SSc incidence, an earlier age of onset, and a greater frequency of interstitial lung disease and pulmonary hypertension $(\mathrm{PH})$ compared to white patients. Data on blacks mostly stem from African Americans and studies on SSc in Asians are mostly from outside Asia and lack direct comparison with other racial groups.

Objectives: We aimed to evaluate differences of SSc presentations between white, Asian and black patients.

Methods: Characteristics of self-reported white, Asians or black SSc patients from the EUSTAR cohort were compared across racial groups; survival and multiple logistic regression analyses were used to adjust for age, sex, disease duration and antibody status.

Results: 9162 white, 341 Asian and 181 black patients were included. Of the Asian patients 208 stem from within Asia and 133 from 34 centres outside Asia; of the black patients 65 stem from within Africa and 116 from 35 centres outside Africa.

Asian and black patients were on average 10 years younger than white patients $(p<0.001)$. Black patients developed the first non-Raynaud's phenomenon (RP) feature of SSc faster than Asian and white patients (all $p<0.01$; figure 1 ) also after adjustment (hazard ratio (HR)[blacks] 1.4, $\mathrm{p}<0.001$; HR[Asians] 1.1, $\mathrm{p}=0.13$ vs whites).

Among ANA specificities, ACA predominated in white patients (whites: $40 \%$, Asians: $16 \%$, blacks: $10 \% ; p<0.001$ ) and Scl-70 in Asian patients (whites: $34 \%$, Asians: $46 \%$, blacks: $32 \%$; $<0.001)$. The prevalence of diffuse skin involvement was similar in Asian (28\%) and white patients (27\%), but more common in black patients univariately $(59 \% ; p<0.001)$; however in multivariable analysis Asian patients were less likely to have diffuse SSc than white patients (OR $0.6, p=0.001$ ) while black patients were more likely (OR2.9, $\mathrm{p}<0.001$ ).

The prevalence of $\mathrm{PH}$ (defined as PAPsys $>40 \mathrm{mmHg}$ as estimated by echocardiography) was similar in the three groups (whites: $13 \%$, Asians: $17 \%$, blacks: $14 \% ; p=0.10$ ); however multivariably, Asians were more likely to have $\mathrm{PH}(\mathrm{OR}$ [Asians] 2.0, $p<0.001$, OR[black] 1.5, $\mathrm{p}=0.13$ vs whites). Asians had a higher prevalence of an impaired diffusing capacity for carbon monoxide (DLCO; $<80 \%$ of predicted; $84 \%)$ than black $(72 \%)$ or white patients $(69 \%, p<0.001)$ also in multivariable analysis (OR[Asians] 3.0, $\mathrm{p}<0.001$; OR[blacks] 1.2, $\mathrm{p}=0.36$ vs whites). Both, Asians ( $43 \%$ ) and black patients (58\%), had a higher prevalence of a reduced forced vital capacity (FVC; $<80 \%$ of predicted) compared to white patients $(23 \%, p<0.001)$ univariably and multivariably (OR[Asians] 2.4, $p<0.001$; OR[blacks] 4.0, $\mathrm{p}<0.001$ vs whites). 